Témoigner Témoigner. Entre histoire et mémoire

Getuigen Revue pluridisciplinaire de la Fondation Auschwitz

$125 \mid 2017$

Histoire et mémoire de la persécution des

homosexuel-le's par les nazis

\title{
Dessins assassins ou la corrosion antisémite (Heinous cartoons)
}

Dessins assassins of een geschiedenis van het antisemitisme in cartoons

\section{Frédéric Crahay}

\section{(2) OpenEdition}

Journals

Édition électronique

URL : https://journals.openedition.org/temoigner/6109

DOI : $10.4000 /$ temoigner.6109

ISSN : 2506-6390

Traduction(s) :

Dessins assassins of een geschiedenis van het antisemitisme in cartoons - URL : https:// journals.openedition.org/temoigner/6110 [nl]

Éditeur :

Éditions du Centre d'études et de documentation Mémoire d'Auschwitz, Éditions Kimé

Édition imprimée

Date de publication : 1 octobre 2017

Pagination : 12-14

ISBN : 978-2-930953-01-4

ISSN : 2031-4183

Référence électronique

Frédéric Crahay, "Dessins assassins ou la corrosion antisémite (Heinous cartoons) », Témoigner. Entre histoire et mémoire [En ligne], 125 | 2017, mis en ligne le 24 décembre 2021, consulté le 03 février 2022. URL : http://journals.openedition.org/temoigner/6109; DOI : https://doi.org/10.4000/temoigner.6109 


\section{DESSINS ASSASSINS OU LA CORROSION ANTISÉMITE (HEINOUS CARTOONS)}

EXPOSITION Depuis le 22 mars 2017, une importante exposition concernant lépineux et ancestral problème de lantisémitisme est hébergée par le Mémorial de Caen. Elle est composée de 170 pièces et documents qui proviennent de la collection privée d'Arthur Langerman, un diamantaire anversois qui a survécu à la Shoah en Belgique.

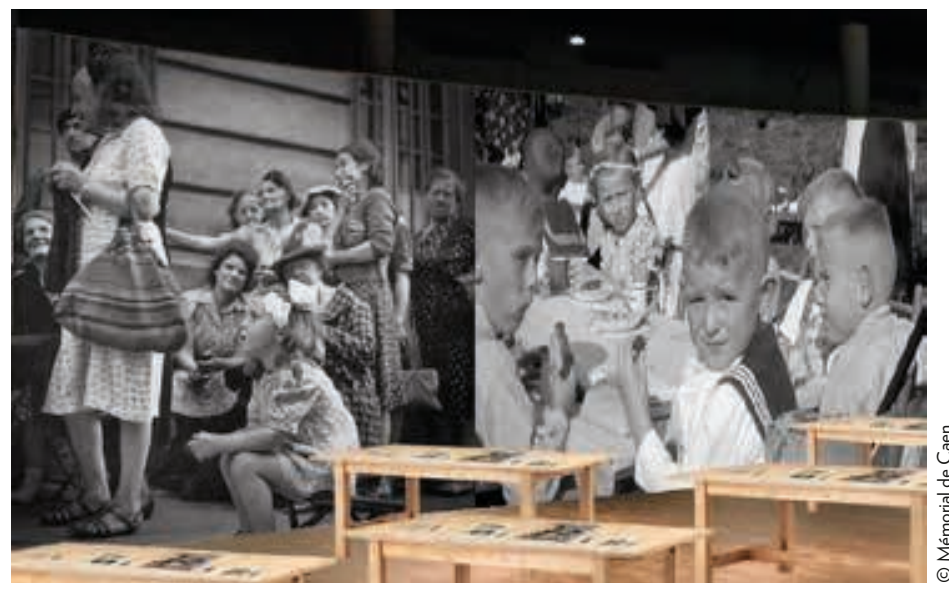

rthur Langerman est né le 21 août 1942 à

A Anvers. Sa famille, qui s'y cachait durant guerre, est arrêtée par la Gestapo le Tes parents, Zysla Blajwas et in a Lan ière à nière de la rue Baron de Castroà Etterbeek. Ce home pon elants (AJB) Sipo-SD. Ses parents sont déportés à Ausch itz-BirSipo-SD. Ses parents sont déportés à Auschwitz-Birkenau pá le Transport XXV, le 19 mai 1944. Son père d'Auschitzà . Sa mère fut transféré en août 1944 chuschitza havensbrick, un canp deconcentration

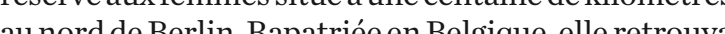
au nord de Berlin. Rapatriée en Belgique, elle retrouva son petit garçon. Traumatisée, elle ne parla jamais de conencen cès d'Adolf

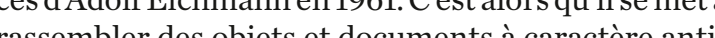
rémite tels que des cart cos postales, affiches, cartoonsenite tels que des cartes postales, anfehes, cartoons, in Sa

aujourd'hui le plus grand fonds privé de pièces antimites au monde.

C'est dans cette riche collection que l'exposition Dessins assassins du Mémorial de Caen puise ses documents. Le visiteur est d'emblée accueilli par une vidéo d’Arthur Langerman qui situe la genèse de sa collection, la raison de son engagement et la volonté en faire une exposition avec des déclinaisons didactiques et pédagogiques. Le parcours, qui se déploie deux etages, explore les documents antisémite Frant de la publication du pamphlet antisemite $L a$ Elam juive découard Drumont, paru en 1886 chez Flammarion, jusqua la fin de la Seconde Guerre mó d'une mise en contexte, ce qui est de prempegné duune mise en contexte, ce qui est de premiere être inter tás les ńssages pronés peuvent parfois étre interprétés enronément par un public non averti. Les lessins, sour de leur force et sont parfois connus du grand public préqu reprises quín ont été faites ultérieurement. stéréotypes anti-jué sontsoume humoristiques, les

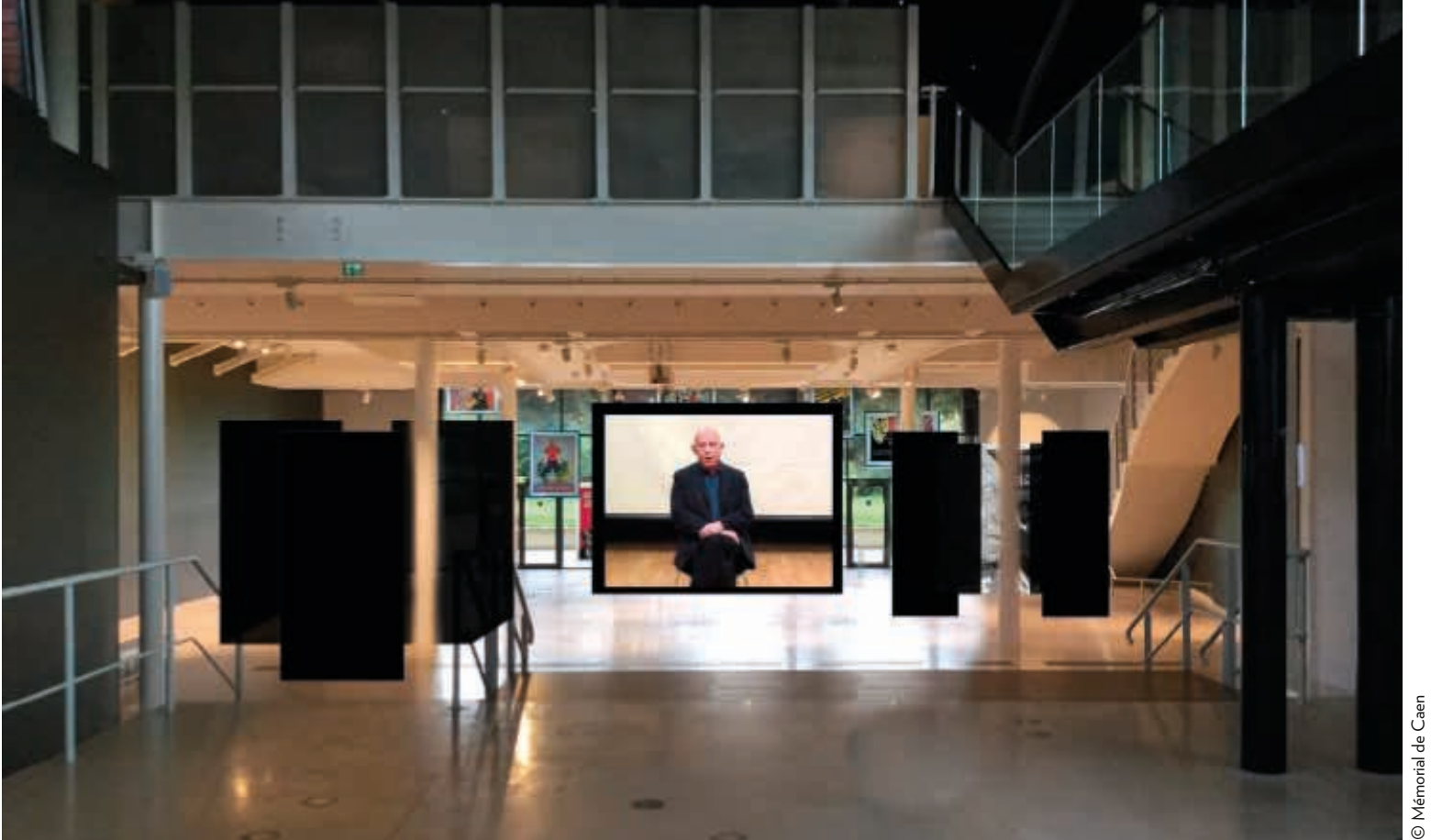

tiques ${ }^{1}$, ce que l'exposition Dessins assassins parvient à bien démontrer au public.

Confronté au problème de l'exhibition d'objets haineux le directeur du Mémorial de Caen et co-concepneux, le directeur du Mémorial de Caen et co-concep-
teur de l'exposition, Stéphane Grimaldi, s'exprime :

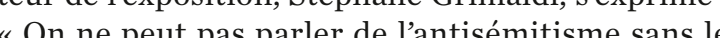
un ne peut pas parle de lantisénitisme sans montrer cos morts ${ }^{2}$ Deśnements rand grand public, telle quelAfaire Dreyfus, sont expliques, ainsique ló joué dans l'histoire de la Tro cisode peu blique françise entre 1894 et 1906 . Les caricesubique françarse entre 18. illich D’autres doç̧on to présentés sont période sombre. Dautré docum ćmitism rabique comme des num

(1) Dessins assassins au Mémorial de Caen, Supplément du dimanche du (2) Ibid., p. 2. l'hebdomadaire nazi qui parut en Allemagne de 1927 1945. Le journal témoigne de pratiques quotidiennes qui ont rendu l'antisémitisme plus « acceptable » pou une frange de la population allemande de l'entre-deuxguerres.

Concevoir et montrer cette exposition ne relève pas d'une évidence. Des institutions comme le Musée juif décliné l'offre de présenter la collection d’Arth Lnt décliné lofre de presenter la colloction darthur provo

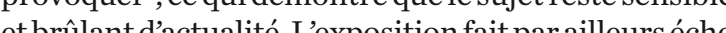
aux ulisations parfis abusives que ailleursecho cestientere contenpo an avant de conclureou d'a

(3) François-Guillaume Lorrain, article paru dans Le Point du Voir: https:///www.pressreader.com/france/le-point/20170323
283613874984791 juif de Bruxelles ou le Mém do da Sho à Pars actur 
• concept qui n’appartient qu'au passé et le visiteur qui prend le temps d'étudier les documents présentés s'en rend bien compte.

Une des forces évidentes de l'exposition (et de la collection Langerman in extenso) est qu'elle présente des documents dans à peu près toutes les langues européennes. Ainsi, les affiches en français ou en néerlandais rapprochent d'un coup le sujet d'un potentiel public belge qu'il soit scolaire ou non. L'exemple est applicable à tous les pays européens qui ont été concernés par l'antisémitisme ou le sont encore de nos jours. C'est d'ailleurs une des volontés pédagogiques de l'exposition que de mettre en exergue les nationalismes européens d'hier et d'aujourd'hui ${ }^{4}$. Un autre but avoué est d'aiguiser l'esprit critique du visiteur lambda et de l'amener à réfléchir sur l'abîme qui sépare les dessins et croquis qui lui sont présentés avec une quelconque démarche humoristique. L'exposition a de ce fait eu le soutien de la Délégation interministérielle à la lutte contre le racisme, l'antisémitisme et la haine antiLGBT (DILCRAH) ${ }^{5}$. L'exposition marque, d'autant plus dans le cadre de l'antisémitisme contemporain qui a connu un regain de visibilité en France avec l'attaque du supermarché Hyper Casher le 9 janvier 2015, un acte parmi d'autres qui visaient clairement la communauté juive en France ou en Belgique si l'on songe à l'attaque contre le Musée juif de Bruxelles commise un an auparavant, le 24 mai 2014.

Cette exposition tellement bien faite, présentet-elle des points faibles? Il y aurait toujours moyen de la compléter en expliquant davantage la différence entre antisémitisme (la haine du Juif pour ce qu'il est) et antijudaïsme (la haine du Juif pour ce qu'il n'est pas - pas Grec, pas Romain, pas Chrétien, etc.). Bien entendu, l'antijudaïsme précède l'antisémitisme qui lui s'est essentiellement développé au XIX ${ }^{\mathrm{e}}$ siècle, ce qui rend plus difficile de trouver des documents pour l'illustrer. L’exposition sera présentée au Mémorial de Caen jusqu'au 15 décembre 2017 pour ensuite devenir itinérante à partir de 2018. Elle est programmée au musée Kazerne Dossin à Malines dans le courant de 2019.

Frédéric Crahay Mémoire d’Auschwitz ASBL
(4) http://www.telerama.fr/scenes/le-stupefiant-cheminement-de-lahaine-antisemite-en-cent-dessins,159234.php.

(5) http://www.memorial-caen.fr/les-evenements/expositionstemporaires/1886-1945-dessins-assassins-ou-la-corrosion-antisemite-eneurope. 